THURSDAY, AUGUST r, IS78

\section{THE ECLIPSE OF THE SUN}

$7 \mathrm{HE}$ following telegram was received from $\mathrm{Mr}$. Lockyer at the moment of going to press. It contains the fullest account of the results of the Eclipse, and of the conclusions arrived at by some of the most eminent of the observers engaged on it, which has yet been published :-

Corona smaller and less brilliant than in 1869 and $187 \mathrm{I}$. Hydrogen faint in corona. Generally invisible, as was also the case in 1874 . Ranyard's polarisation confirmed Young's law, both(?)and lines brilliant. Corona probably photographed in Siam (?). Fluorescent eyepiece worked well. Bright line near $B$; heat line in ultra red by thermopile. Watson's Vulcan, Right ascension $8^{\circ} 26^{\prime}$, declination $18^{\circ}$ N. Result-lower temperature of corona gas, as confined to chromosphere; almost entirely continuous spectrum, isolated from gaseous spectrum. Corona changes with sun-spots, and prominences increased. Continuation of absorption with deficit in ejected hot matter induces solar radiation. Young, Watson, Draper, Loskyer cable above.

The following telegram appears in the Daily News of yesterday from its special correspondent at Rawlings, Wyoming, U.S., under date July 29 :-

The eclipse bas been most satisfactorily observed at all the northern stations, and at all the southern ones from which news has been received up to the present time.

The corona was markedly different from those observed in 1869,1870 , and $187 \mathrm{r}$, and this year the observations have demonstrated the great variation in the structure and condition of the sun's outer atmosphcre when there are most and fewest spots on his disc. The corona was small, of a pearly lustre, and the indications of definite structure were limited to two portions. Several long rays were seen, and Prof. Newcomb, who had erected a screen on a high pole, thinks he detected the zodiacal light extending six degrees from the sun. Prof. Draper, who used a Rutherfurd grating two inches square and a camera of large aperture, and Mr. Lockyer, who placed a small grating in front of an ordinary portrait camera, both obtained photographs of the spectrum of the corona. A continuous spectrum only was recorded, and in ordinary spectroscopes the bright lines usually seen were altogether absent. Mr. Lockyer, who observed with a simple grating, saw no rings.

All these are so many indications of a wonderful change since $187 \mathrm{I}$, and there is great probability that the substance which gives rise to the continuous spectrum is not that which produces any of the lines.

Prof. Newcomb's party and Prof. Barker made a careful search for the dark lines in the corona, but none were observed. Prof. Young has telegraphed that there were no lines observed in the ultra violet at Denver. It would appear, therefore, that he also bas obtained photographic evidence of a continuous spectrum. The radial polarisation observed in $187 \mathrm{I}$ has been confirmed by Prof. Holden.

A new use of the eclipse has been introduced on this occasion. Professors Newcomb, Watson, Holden, and others have included a search for intramercurial planets

Vol. xyili.-No. 457 in their programme, and Prof. Watson has been fortunate enough to detect a body of four and a half magnitude near the sun, which certainly is neither a known star nor a planet.

Every facility has been afforded to the astronomers, and a fourth station along the northern line crossing the belt of totality was at the last moment organised by the Union Pacific travelling photographic car being run to a point between the Eclipse camps at Separation and Preston.

The tasimeter, the new instrument on which $\mathrm{Mr}$. Edison has been working unceasingly here, has proved its delicacy. During the eclipse he attached Thomson's galvanometer, the index being set to zero, when the telescope carrying the tasimeter was pointed several degrees from the sun. The point of light rapidly left the scale, when the corona was brought upon the fine slit by which the tasimeter itself was protected. There was no chromosphere to speak of, and only one prominence, like the horn observed in 1868 , but very dim.

\section{OUR NATURAL HISTORY COLLECTIONS}

O $\mathrm{N}$ referring to the "Bill to enable the Trustees of the British Museum to remove Portions of their Collection," our readers will see that our correspondent, "Naturalist," in our last issue (p. 328), is correct in supposing that this measure contemplates no change whatever in the administration of the natural history collections when placed on their new site in South Kensington. The fourth clause of the Bill expressly reserves all the "rights, powers, duties, and obligations" of the fifty trustees, except as regards the mere removal of the portions of the collections specified in the schedule. And we must agree with our correspondent that this measure will be directly contrary to the opinion of many of our leading naturalists, and to the recommendations of the Royal Science Commission.

As regards the first point, it is only necessary to refer to the memorial presented to the Chancellor of the Exchequer in I866, when the subject of the removal of the natural history collection was under discussion. The memorial, which was drawn up primarily in support of the removal of the natural history collections from the rest of the British Musetum, and is signed by $\mathrm{Mr}$. Bentham, Mr. Darwin, Sir J. Hooker, Prof. Huxley, and other well-known names, states that in the opinion of the memorialists "it is of fundamental importance to the progress of the natural sciences in this country that the administration of the natural history collections should be placed under one officer, who should be immediately responsible to one of the Queen's ministers." The Bill as drawn proposes to leave the natural history collections exactly as they are, under the rule of fifty trustees responsible to $n o$ one but to themselves.

Let us now turn to the Fourth Report of the "Royal Commission on Scientific Instruction and the Advancement of Science," issued in 1874 , in which the affairs of the British Museum, and more especially of the natural history collections belonging to it, are discussed. After an exhaustive account of the circumstances of the case and an analysis of the evidence given before then by the 